\title{
Surface Chemistry of HNCO and NCO on Pd(100)
}

\author{
R. Németh, J. Kiss,* and F. Solymosi \\ Institute of Solid State and Radiochemistry, University of Szeged and Reaction Kinetics Research Group of the \\ Hungarian Academy of Sciences, P.O. Box 168, H-6701 Szeged, Hungary
}

Received: July 14, 2006; In Final Form: November 3, 2006

\begin{abstract}
The interaction of HNCO with $\mathrm{Pd}(100)$ has been studied with reflection absorption infrared spectroscopy. Following the adsorption of $\mathrm{HNCO}$ at $100 \mathrm{~K}$, a fraction of the adsorbed HNCO desorbs at $115-125 \mathrm{~K}$ and another part dissociates at 120-140 K yielding adsorbed $\mathrm{H}$ and NCO species. NCO locates in top-site position having significant lateral repulsive interaction between them. On clean surface, the NCO species was found to decompose readily to adsorbed $\mathrm{CO}$ and $\mathrm{N}$ on warming to $300 \mathrm{~K}$. Preadsorbed oxygen atoms resulted in the significant stabilization of NCO; the asymmetric stretch of it was detected up to $380 \mathrm{~K}$. Neither NCO nor $\mathrm{HNCO}$ were identified in the $\mathrm{NO}+\mathrm{CO}$ reaction even at high pressure $(1-10 \mathrm{mbar})$ and at elevated temperature $(500-650 \mathrm{~K})$. The presence of hydrogen did not help the formation of this species.
\end{abstract}

\section{Introduction}

In the clarification of the mechanism of catalytic reactions, it is of fundamental importance to establish the nature of surface intermediates formed during the reaction. In the $\mathrm{NO}+\mathrm{CO}$ reaction on supported metals isocyanate, $\mathrm{NCO}$, species has been detected by means of infrared spectroscopy. ${ }^{1-6}$ Subsequent works disclosed several details on the chemistry of NCO species. ${ }^{7-12}$ These are as follows: (1) the asymmetric stretch of NCO sensitively depends on the nature of the support; the highest frequency, $2305 \mathrm{~cm}^{-1}$, was registered on silica, and the lowest one at $2210 \mathrm{~cm}^{-1}$ was registered for titania-supported Pt metals. ${ }^{8-10}$ (2) The amount of NCO exceeds by more than 1 order of magnitude the number of surface Pt atoms. ${ }^{7}$ In the explanation of this finding, it was assumed that the NCO was formed on the metal, but after its formation, it spilled over onto the support, where it could be accumulated. ${ }^{7-12}$ Isocyanate surface-bound molecule has been identified in a huge number of subsequent papers dealing with the reduction of $\mathrm{NO}$ with $\mathrm{CO}$ or hydrocarbons. The positions of the bands were the same as determined before on various oxides indicating the migration of NCO from the metal onto the support. A significant step forward was made when $\mathrm{NCO}$ was prepared and examined on metal single-crystal surfaces in ultrahigh vacuum (UHV). This was first achieved by the adsorption and dissociation of HNCO. ${ }^{13-16}$ These studies disclosed that the NCO species on Pt metals is quite unstable; it decomposes completely at 300$350 \mathrm{~K}$. The asymmetric stretch of NCO was found in the range of $2160-2190 \mathrm{~cm}^{-1} \cdot{ }^{13-16}$ Another finding was that the adsorbed oxygen extends its stability region. ${ }^{16} \mathrm{NCO}$ species was also detected on single crystals using high pressure of $\mathrm{NO}+\mathrm{CO}^{17-20}$ and in the oxidation of adsorbed CN. ${ }^{21-24}$ The location of the NCO band fell in the range of $2160-2204 \mathrm{~cm}^{-1}$. According to a recent density functional theory $\operatorname{study}^{25}$ (DOS), the wavenumber of the predicted asymmetric mode for NCO adsorbed on $\mathrm{Cu} 2187 \mathrm{~cm}^{-1}$, which matches quite well to the experimentally observed value.

Recently, Ozensoy et al. and Hess et al. have reported an interesting finding, namely, the appearance of a strong band

* Author to whom correspondence should be addressed. Fax: +36-62420-678; e-mail: jkiss@chem.u-szeged.hu. around $2256 \mathrm{~cm}^{-1}$ formed in the high-temperature (500-650 $\mathrm{K})$ reaction of $\mathrm{NO}+\mathrm{CO}$ on $\mathrm{Pd}(111)$ using in-situ polarization modulation infrared absorption spectroscopy (PM-IRAS). ${ }^{26,27}$ The position and the stability of the band, however, were not in harmony with the previous results obtained on supported $\mathrm{Pt}$ metals ${ }^{7-12}$ and on various metal single crystals. ${ }^{13-20}$ We pointed out our concern in a comment. ${ }^{28}$ Afterward, the results were reinterpreted, and the band at $2256 \mathrm{~cm}^{-1}$ was attributed to the vibration of $\mathrm{HNCO} .{ }^{29}$ According to the assumption, hydrogen originated from the bulk of the Pd crystal, as the reacting gas mixture contained no hydrogen.

In the present work, NCO species is produced on $\operatorname{Pd}(100)$ by the low-temperature adsorption and dissociation of $\mathrm{HNCO}$ with the aim of determining the position and stability of the $\mathrm{NCO}$ on this surface. We also pay attention to the effect of $\mathrm{CO}$, hydrogen, and oxygen on the behavior of NCO. Some measurements are also made with $\mathrm{NO}+\mathrm{CO}$ gas mixture.

\section{Experimental}

The experiments were performed in a two-level UHV system with a base pressure of $5 \times 10^{-10}$ mbar. The lower part of the chamber had facilities for Auger electron spectroscopy (AES) and temperature-programmed desorption (TPD). The upper part was equipped with a single-beam Fourier transform IR (FTIR) spectrometer (Mattson Unicam, Research Series), which was used for reflection absorption infrared spectroscopy (RAIRS) measurements. All IR spectra were averaged over 512-1024 scans using an MCT detector at $4 \mathrm{~cm}^{-1}$ resolution. Sample spectra were ratioed against a background taken after flashing the crystal to $1200 \mathrm{~K}$. The upper part of IR cell allowed us to study the surface processes at high pressures (up to 50 mbar) and high temperatures. The whole optical path was purged with $\mathrm{CO}_{2}$ - and $\mathrm{H}_{2} \mathrm{O}$-free air generated by a Balston 75-62 FT-IR purge gas generator. The high-pressure IR section could be quickly evacuated by differential pumping. After a short pumping, the sample could be moved to the UHV section to carry out AES and TDS measurements.

The palladium single crystal was cleaned by cycles of argon ion bombardment at $650 \mathrm{~K}$ (current: $10 \mu \mathrm{A}$, energy: $1.5 \mathrm{kV}$ ) 

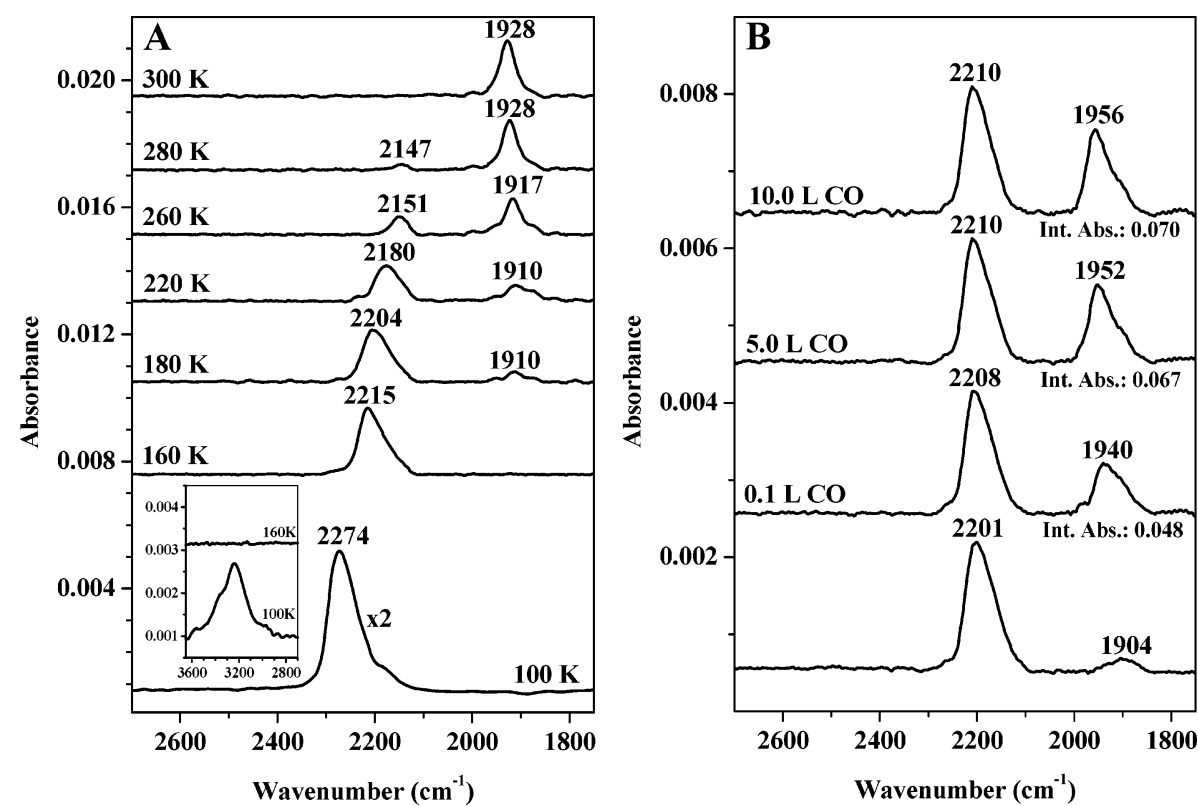

Figure 1. (A) RAIR spectrum of adsorbed HNCO on a clean $\operatorname{Pd}(100)$ surface and effects of annealing on the adsorbed layer. The insert shows the $\mathrm{N}-\mathrm{H}$ regime. (B) Effects of postdosed $\mathrm{CO}$ on the frequencies of NCO vibration. NCO was produced at $160 \mathrm{~K}$ and then different amounts of CO were introduced.

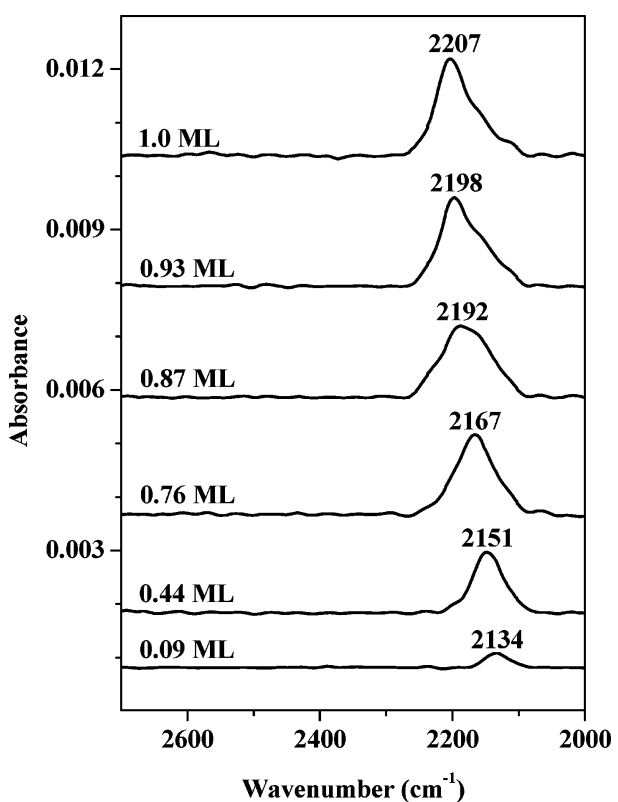

Figure 2. Effects of HNCO coverage on the vibration frequencies of $\mathrm{NCO}$ at $160 \mathrm{~K}$

and short annealing to $1200 \mathrm{~K}$. The main impurities (S, P, and $\mathrm{C})$, as detected by AES on the (100) face, were removed. The gases used in the experiments were $\mathrm{NO}, \mathrm{CO}, \mathrm{O}_{2}, \mathrm{~N}_{2} \mathrm{O}$, and $\mathrm{H}_{2}$, which were of $99.99 \%$ purity. The preparation of $\mathrm{HNCO}$ followed the procedure of Ashby and Werner ${ }^{30}$ which involves the dropwise addition of a saturated aqueous solution of potassium cyanate (KOCN, BDH Chemicals, $98 \%$ purity) to concentrated phosphoric acid (Baker, $85 \%$ by weight in water) under vacuum. The $\mathrm{HNCO}$ vapor produced in this reaction was condensed at $190 \mathrm{~K}$ cooled by a dry ice/acetone bath under dynamic vacuum conditions. This product was twice statically vacuum distilled from 240 to $190 \mathrm{~K}$ to remove mostly $\mathrm{CO}_{2}$, $\mathrm{NH}_{3}$, and $\mathrm{H}_{2} \mathrm{O}$ impurities. The purity of $\mathrm{HNCO}$ has been checked by MS: water was not detected. The HNCO was stored at $\mathrm{LN}_{2}$ temperature.

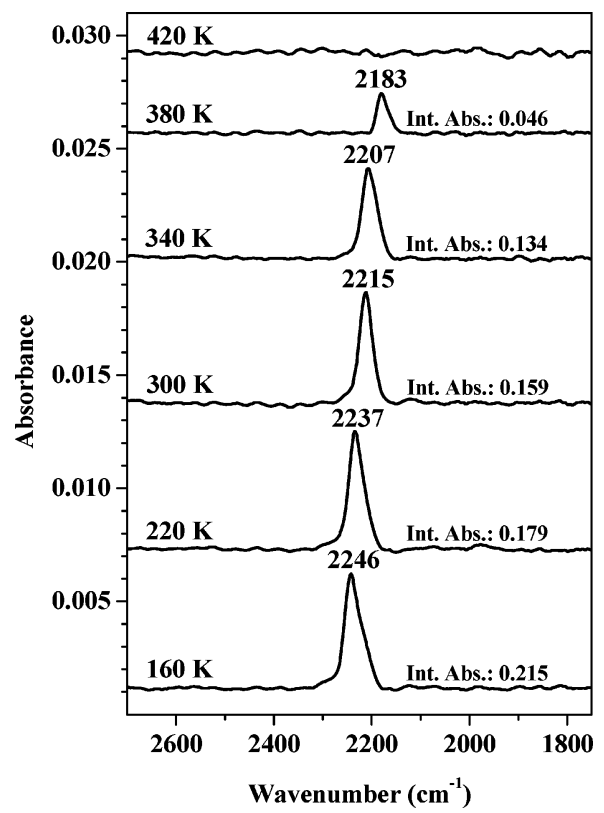

Figure 3. Effects of preadsorbed oxygen on the position and stability of the NCO band. Oxygen was added at $300 \mathrm{~K}$. The oxygen coverage was $\theta_{0} \sim 0.5 \mathrm{ML}$.

\section{Results and Discussions}

3.1. Adsorption and Dissociation of HNCO on Clean Pd(100). In the first experimental series, HNCO was adsorbed at $100 \mathrm{~K}$. Spectra are displayed in Figure 1A. At low HNCO exposure, $6.0 \mathrm{~L}$, we obtained only one absorption band at 2274 $\mathrm{cm}^{-1}$ because of the asymmetric stretch of molecularly adsorbed HNCO. With the increase of the HNCO exposure $(18 \mathrm{~L})$, other absorption bands appeared at 3374 and $3240 \mathrm{~cm}^{-1}$ because of $\mathrm{N}-\mathrm{H}$ stretches (not shown). ${ }^{23,31}$ It is remarkable that the bands of $\mathrm{N}-\mathrm{H}$ vibration developed only at higher exposures, which may indicate that at submonolayer coverage the $\mathrm{N}-\mathrm{H}$ axis (but not the NCO group) is parallel to the surface.

When the sample was heated to $160 \mathrm{~K}$, the bands at 2274 , 3374 , and $3240 \mathrm{~cm}^{-1}$ were completely eliminated and a new peak developed at $2215 \mathrm{~cm}^{-1}$. On the basis of previous studies, 

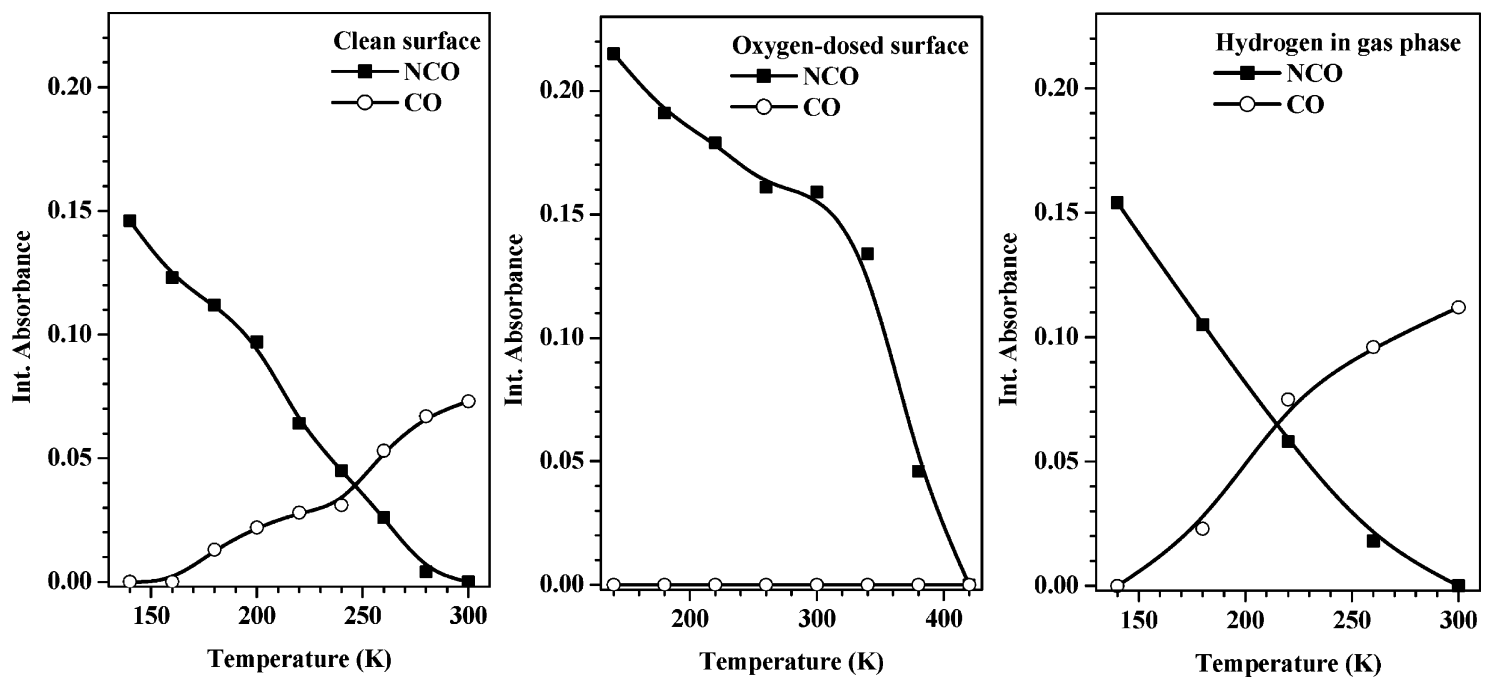

Figure 4. Integral absorbance changes of $\mathrm{NCO}$ and $\mathrm{CO}$ with the temperature on clean and oxygen-dosed surface and in the presence of hydrogen in the gas phase.

we attribute this feature to the asymmetric stretch of adsorbed NCO formed in the dissociation of molecularly bonded HNCO. At $180 \mathrm{~K}$, another peak was detected at $\sim 1910 \mathrm{~cm}^{-1}$, which is, no doubt, due to the vibration of bridged $\mathrm{CO}$ produced by the decomposition of NCO species. Further increase in the annealing temperature led to the shift of the $2215 \mathrm{~cm}^{-1}$ band to lower frequencies on one hand and to its attenuation on the other hand. At the same time, the CO band at $1910 \mathrm{~cm}^{-1}$ became more intense. The NCO band completely disappeared at $300 \mathrm{~K}$, which is in harmony with the stability of NCO bonded on other Pt metals. ${ }^{13-20}$ These spectral changes are also shown in Figure 1A.

For the explanation of the above shift of the NCO band, we consider two possibilities: an electronic and a geometric factor. Results presented in Figure 1B show that postdosed CO did not influence the position of the NCO band, and preadsorbed NCO had no effect on the location of the CO band. These findings suggest that the adsorption sites for $\mathrm{NCO}$ and $\mathrm{CO}$ are different. CO bonds in hollow sites, ${ }^{32}$ while NCO bonds in top sites. In other words, adsorbed $\mathrm{CO}$ is not responsible for the observed move in the position of the $\mathrm{NCO}$ peak. When the $\mathrm{CO}$ was predosed (in this case $\mathrm{CO}$ bonds preferentially in bridge sites), ${ }^{32}$ the extent of the dissociation of HNCO was reduced very likely by the site-blocking effect of $\mathrm{CO}$, but the vibration frequency for NCO remained unaltered.

In Figure 2, we demonstrate the coverage dependence of the band because of asymmetric NCO stretching frequencies. For the production of different coverages, the surface was dosed at $100 \mathrm{~K}$ with $\mathrm{HNCO}$, and then the sample was heated to $160 \mathrm{~K}$, where only NCO and adsorbed $\mathrm{H}$ remained on the surface. This process was repeated several times with longer and longer dosing times to increase the coverage of NCO on Pd. When the position and the area of NCO band did not change, that is, the possible saturation of the surface with NCO was achieved, this state was considered as a monolayer coverage of NCO. Spectra taken at $160 \mathrm{~K}$ after shorter dosing time exhibited NCO band of smaller area. The coverage of the NCO was calculated from the ratio of the intensity of this band to that obtained at saturation. As Figure 2 shows, at low coverage the NCO band appeared at $2134 \mathrm{~cm}^{-1}$. On increase of its surface concentration, the band gradually shifted to higher frequencies. From this feature, we may conclude that there is a strong lateral repulsive interaction between $\mathrm{NCO}$ groups resulting in a significant blue shift in the RAIR spectra. This kind of shift was not experienced on the most closed packed $\mathrm{Rh}(111) .{ }^{16}$

TPD measurements indicated that the adsorbed HNCO desorbed with a peak temperature of $115 \mathrm{~K}$ (denoted with $\alpha$ ) which cannot be saturated. This is the sign of the formation of a condensed layer. In addition, we also detected a shoulder at $125 \mathrm{~K}$ (denoted with $\beta$ ), which is very likely due to the weakly bonded HNCO. At higher temperature, the release of $\mathrm{CO}$ with $\mathrm{Tp}=450 \mathrm{~K}$ and that of $\mathrm{N}_{2}$ between 630 and $700 \mathrm{~K}$ also occurred. $\mathrm{CN}$ containing groups, such as $\mathrm{C}_{2} \mathrm{~N}_{2}$, were not observed.

3.2. Effects of $\mathrm{O}_{2}$ and $\mathrm{H}_{2}$ on the Stability of NCO. In this experimental series, the $\mathrm{Pd}(100)$ surface was saturated with $\mathrm{O}_{2}$ at $300 \mathrm{~K}$. In this way, the highest coverage of adsorbed oxygen on $\mathrm{Pd}(100)$ corresponds to $0.5 \mathrm{ML} .{ }^{33,34}$ Exposure of this $\mathrm{Pd}$ surface to $\mathrm{HNCO}(18 \mathrm{~L})$ at $100 \mathrm{~K}$ produced a band at 2270 $\mathrm{cm}^{-1}$ characteristic of molecularly bonded HNCO. After the removal of $\mathrm{HNCO}$ by heating the sample to $160 \mathrm{~K}, \mathrm{NCO}$ band appeared at $2246 \mathrm{~cm}^{-1}$. The results are displayed in Figure 3. The intensity of the band was more than $30 \%$ higher than that observed on a clean surface. This indicates that preadsorbed oxygen facilitated the dissociation of HNCO. The position of the band appeared at higher frequency, $2246 \mathrm{~cm}^{-1}$, compared to the clean surface (Figure 2). Its location and integral absorbance underwent only slight change up to $280 \mathrm{~K}$ on oxygen predosed surface. On additional heating, the NCO band slightly attenuated. Its band was finally centered at $2183 \mathrm{~cm}^{-1}$ and disappeared only at $420 \mathrm{~K}$, that is, at significantly higher temperature than in the case of a clean surface. This suggests that preadsorbed oxygen enhances the stability of the isocyanate species on Pd(100) surface. This is clearly demonstrated by the intensity data versus annealing temperature plot shown in Figure 4. The stabilizing effect of adsorbed oxygen on the NCO species was first experienced on $\operatorname{Rh}(111),{ }^{16}$ and later it was also observed on other metal surfaces. ${ }^{17-19}$ The absence of the CO band in the spectra indicates that $\mathrm{CO}$ formed in the decomposition of NCO reacts immediately with preadsorbed oxygen, and $\mathrm{CO}_{2}$ formed was released in the gas phase.

For this stabilization phenomenon, several explanations were considered. As was assumed in the case of $\mathrm{Rh}(111),{ }^{16} \mathrm{NCO}$ species is affected by a strong electric field induced by adsorbed oxygen atoms. Kreuzer and Wang ${ }^{35,36}$ have shown that the binding of adsorbed species to the surface can be strongly influenced by an external field. As a result of this effect, NCO 
species can be converted into a more ionic form leading to higher stability. Oxygen adatoms could also block sites required for the adsorption of dissociation products, $\mathrm{CO}$ and $\mathrm{N}$ atom. It is conceivable that the combined influence of these factors leads to the stabilization of the NCO species.

As regards the effect of hydrogen, we found that the saturation of the surface with hydrogen at $300 \mathrm{~K}$ shifts the complete dissociation of $\mathrm{HNCO}$ from 140 to $220 \mathrm{~K}$. When the sample containing $\mathrm{NCO}$ species (produced by $\mathrm{HNCO}$ dissociation at $160 \mathrm{~K}$ ) was heated in a stepwise manner in the presence of $10^{-6}$ mbar of hydrogen up to $300 \mathrm{~K}$, that is, to the elimination temperature of $\mathrm{NCO}$, we observed practically the same features as in the absence of hydrogen (Figure 4). This means that hydrogen does not have any observable influence on the NCO stability in this low-temperature range.

3.3. Interaction of $\mathrm{NO}+\mathrm{CO}$ Gas Mixture on $\operatorname{Pd}(100)$. An attempt was also made to produce NCO species on the Pd(100) facet by the $\mathrm{NO}+\mathrm{CO}$ reaction in the high-pressure chamber. The surface was exposed to 10 mbar $\mathrm{NO}+\mathrm{CO}$ mixture (NO:CO $=2: 3$ ) at $300 \mathrm{~K}$ and then was heated to higher temperatures in a stepwise manner. The spectra were recorded at selected temperatures. The reaction sets in at $500 \mathrm{~K}$ as indicated by the formation of $\mathrm{CO}_{2}, \mathrm{~N}_{2}$, and $\mathrm{N}_{2} \mathrm{O}$ in the gas phase. In addition to the peaks of the reactants $\left(\mathrm{CO}\right.$ at $1967 \mathrm{~cm}^{-1}$, NO at $1658-1635 \mathrm{~cm}^{-1}$ ), we also detected the absorption bands of the products in the RAIR spectra, $\mathrm{CO}_{2}$ band at $2349 \mathrm{~cm}^{-1}$ and $\mathrm{N}_{2} \mathrm{O}$ band at $2235 \mathrm{~cm}^{-1}$. These peaks were easily eliminated from the spectra after degassing the sample at $300 \mathrm{~K}$. The most important observation, however, is that there were no absorption bands attributable to $\mathrm{NCO}$ or HNCO. This is harmony with the results obtained following $\mathrm{HNCO}$ adsorption on this $\mathrm{Pd}(100)$ sample. If we take into account the results of Ozensoy et al. and Hess et al., ${ }^{26,27}$ and accept their modified interpretation, ${ }^{29}$ namely, that the $2256 \mathrm{~cm}^{-1}$ band is due to $\mathrm{HNCO}$, we can conclude that our $\mathrm{Pd}(100)$ single crystal contains no or not sufficient amount of dissolved hydrogen to produce $\mathrm{HNCO}$. Interestingly, the formation of the band at 2256-2270 $\mathrm{cm}^{-1}$ did not occur even when we added $5.0 \mathrm{mbar}_{2}$ to the $\mathrm{NO}+$ $\mathrm{CO}$ reacting gas mixture. The characteristic band of $\mathrm{HNCO}$ was eliminated far below room temperature (Figure 3), whereas the feature at $2256 \mathrm{~cm}^{-1}$ remained stable even after reducing the chamber pressure to $1 \times 10^{-7} \mathrm{mbar}$ at $300 \mathrm{~K} .^{26,27}$ In the light of the results of the present and previous works, ${ }^{7-20}$ we feel that further studies are clearly needed to ascertain the development of the $2256 \mathrm{~cm}^{-1}$ band evolved in the high-temperature reaction of $\mathrm{NO}+\mathrm{CO}$ on $\mathrm{Pd}(111)$.

\section{Conclusion}

1. HNCO adsorbs dissociatively on clean $\operatorname{Pd}(100)$ above 120-140 K forming hydrogen and NCO species. Strong repulsive interaction was observed between NCO species.

2. NCO surface species formed is very unstable on a clean surface: it totally decomposes to adsorbed CO (hollow site) and $\mathrm{N}$ atoms at $280-300 \mathrm{~K}$.
3. Oxygen adatoms enhance the stability region of $\mathrm{NCO}$, but even in the presence of high oxygen coverage, the NCO band disappeared between 380 and $420 \mathrm{~K}$.

4. There was no sign of NCO formation in the hightemperature reaction of $\mathrm{NO}+\mathrm{CO}$ gas mixture on $\mathrm{Pd}(100)$ at $500-650 \mathrm{~K}$ even using high pressure $(1-10 \mathrm{mbar})$ of the reactants. The presence of hydrogen did not promote the formation of either $\mathrm{NCO}$ or $\mathrm{HNCO}$ on this Pd surface.

Acknowledgment. This work is supported by the OTKA Grant T/16 46351 and 28000R 201 KNRET project.

\section{References and Notes}

(1) Unland, M. L. J. Catal. 1973, 31, 459.

(2) Unland, M. L. J. Phys. Chem. 1973, 77, 1952.

(3) London, J. W.; Bell, A. T. J. Catal. 1973, 31, 96

(4) Solymosi, F.; Sárkány, J. React. Kinet. Catal. Lett. 1975, 3, 297.

(5) Brown, M. F.; Gonzalez, R. D. J. Catal. 1976, 44, 477.

(6) Solymosi, F.; Sárkány, J.: Schauer, A. J. Catal. 1977, 46. 297.

(7) Solymosi, F.; Kiss, J.; Sárkány, J. In Proceedings, 7th International Vacuum Congress and 3rd International Conference on Solid Surfaces. Vienna, Austria, 1977; Elsevier, p 819

(8) Solymosi, F.; Bánsági, T. J. Phys. Chem. 1979, 83, 552

(9) Solymosi, F.; Völgyesi, L.; Sárkány, J. J. Catal. 1987, 54, 336. 79.

(10) Solymosi, F.; Völgyesi, L.; Raskó, J. Z. Phys. Chem. 1980, 120,

(11) Bánsági, T.; Raskó, J.; Solymosi, F. In Proceedings of the International Symposium on Spillover of Adsorbed Species, Lyon, 1983; Pajnok, G. M., Teicher, S. J., Germain, J. E., Eds.; Elsevier Sci. Publ. B.V.: Amsterdam, 1983; p 109.

(12) Hecker, W. C.; Bell, A. T. J. Catal. 1984, 85, 389

(13) Solymosi, F.; Kiss, J. Surf. Sci. 1981, 108, 641.

(14) Gorte, R. J.; Schmidt, L. D.; Sexton, B. A. J. Catal. 1981, 67, 387

(15) Kiss, J.; Solymosi, F. Surf. Sci. 1983, 135, 243

(16) Kiss, J.; Solymosi, F. J. Catal. 1998, 179, 277.

(17) Kostov, K. L.; Jacob, P.; Rauscher, H.; Menzel, D. J. Phys. Chem 1991, 95, 7785

(18) Kostov, K. L.; Rauscher, H.; Menzel, D. Surf. Sci. 1993, 287/288, 283.

(19) Jakob, P. Chem. Phys. Lett. 1996, 263, 607

(20) Miners, J. H.; Bradshaw, A. M.; Gardner, P. Phys. Chem. Chem. Phys. 1999, 1, 4909.

(21) Solymosi, F.; Kiss, J. Surf. Sci. 1981, 108, 368.

(22) Solymosi, F.; Berkó, A. Surf. Sci. 1982, 122, 291.

(23) Celio, H.; Mudalige, K.; Millis, P.; Trenary, M. Surf. Sci. 1997 394, L168.

(24) Solymosi, F.; Kiss, J. Surf. Sci. 1981, 104, 181.

(25) Garda, G. R.; Ferullo, R. M.; Castellani, N. J. Surf. Sci. 2005, 598 ,

(26) Ozensoy, E.; Hess, C.; Goodman, D. W. J. Am. Chem. Soc. 2002, 124,8524 .

(27) Hess, C.; Goodman, D. W.; Ozensoy, E. J. Phys. Chem. B 2003, 107,2759

(28) Solymosi, F.; Bánsági, T.; Süli Zakar, T. J. Phys. Chem B 2004 108,14178

(29) Hess, C.; Ozensoy, E.; Goodman, D. W. J. Phys. Chem. B 2004 108,14181 .

(30) Ashby, R. A.; Werner, R. L. J. Mol. Spectrosc. 1965, 18, 184.

(31) Hertzberg, G.; Reid, C. Discuss. Faraday Soc. 1950, 9, 92. [Reid, C. Chem. J. Phys. 1950, 18, 1544.]

(32) Bradshaw, A. M.; Hoffman, F. M. Surf. Sci. 1978, 72, 513

(33) Orient, T. W.; Bader, S. D. Surf. Sci. 1982, 115, 323

(34) Vu, D. T.; Mitchell, K. A. R.; Warren, O. L.; Thiel, P. A. Surf. Sci. 1994, 318,129

(35) Kreuzer, H. J. In Chemistry and Physics of Solid Surfaces: Vanselow, R., Howe, R., Eds.; Spinger: Berlin, 1990; p 133.

(36) Kreuzer, H. J.; Wang, L. C. J. Chem. Phys. 1990, 93, 6065. 